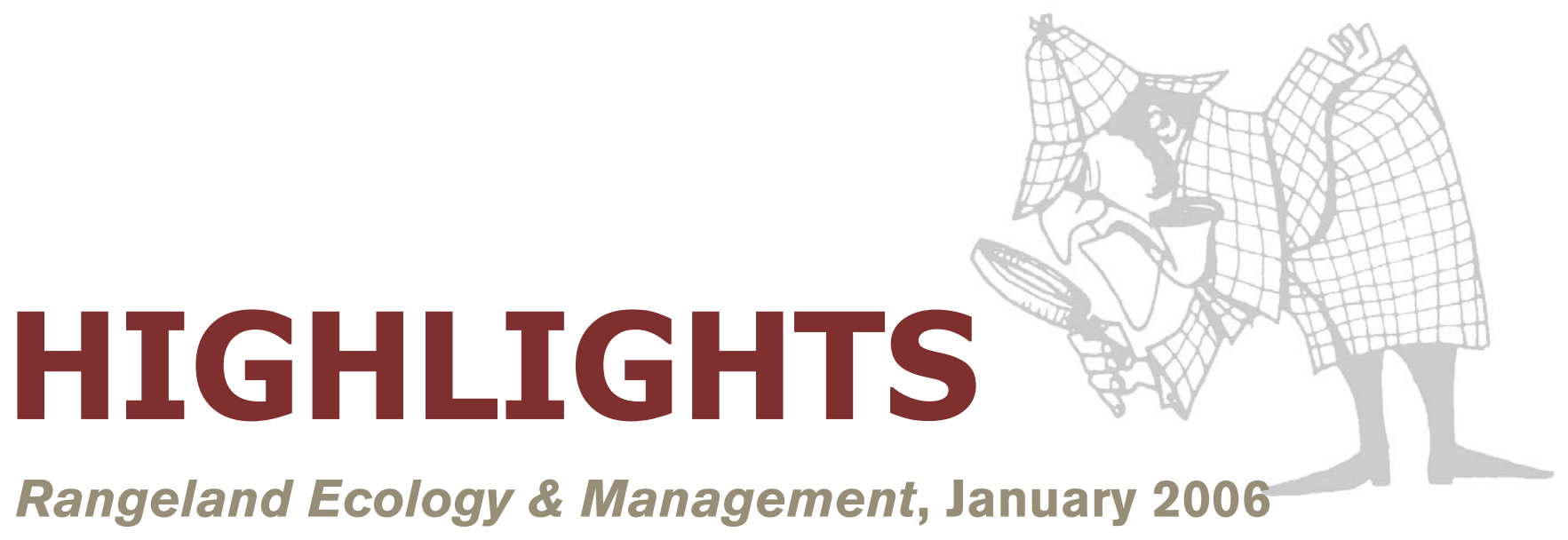

\section{Applying Improved Estimates of MODIS Productivity to Characterize Grassland Vegetation Dynamics}

\section{Matthew C. Reeves, Maosheng Zhao, and} Steven W. Running

The efficacy of Moderate Resolution Imaging Spectroradiometer (MODIS)-derived vegetation productivity was tested to characterize fluctuations in aboveground green biomass and provide regional perspectives of interannual vegetation dynamics. The relationships between MODIS net photosynthesis estimates and scaled aboveground green biomass improved steadily during the progression of each growing season $\left(r^{2}=0.77\right.$ and 0.57 in 2001 and 2002, respective1y). We characterized interannual variability in grassland vegetation through analysis of MODIS-derived net primary productivity for the years 2001 to 2003. MODIS data may be more useful for addressing administrative, rather than managerial, needs given the coarse resolution and regional perspective of the vegetation products.

\section{Comparison of Stocking Rates From Remote Sensing and Geospatial Data}

\section{E. Raymond Hunt Jr. and Brian A. Miyake}

Remote sensing data from the Advanced Very High Resolution Radiometer have coarse spatial resolution and high temporal resolution, which can be used to estimate regional net primary production. The 12 -year average of net primary production was used to calculate stocking rates in animal-unit months per acre for the state of Wyoming. Stocking rates were also calculated from 1:500,000-scale soil and climate geospatial data layers based on stocking rates from the US Department of Agriculture Natural Resource Conservation Service. Remote sensing indicates the actual condition of vegetation, so this is an important step in the development of regional forecasting of range condition, trend, and projected stocking rates.

\section{A Protocol for Retrospective Remote Sensing- Based Ecological Monitoring of Rangelands}

Robert A. Washington-Allen, Neil E. West, R. Douglas Ramsey, and Rebecca A. Efroymson

The degree of rangeland degradation in the United States is unknown because of the failure of traditional field-based monitoring to capture the range of variability of ecological indicators and disturbances at regional to national spatial scales and temporal scales of decades. Consequently, a protocol is presented for retrospective monitoring and assessment of rangeland degradation using historical time-series of remote sensing data and catastrophe theory as an ecological framework. Characteristics of land degradation were retrospectively measured for a nearly 33-year trend using surrogate remote-sensing-based indicators that correlate with changes in life-form composition, vegetation productivity, accelerated soil erosion, soil quality, and landscape.

\section{Evaluation of High-Resolution Satellite Imagery for Assessing Rangeland Resources in South Texas}

\section{J. H. Everitt, C. Yang, R. S. Fletcher, and D. L. Drawe}

Because of the generally great expanse and inaccessibility of rangelands, determining their botanical characteristics by ground surveys is time consuming and expensive. QuickBird high-resolution $(2.8 \mathrm{~m})$ satellite imagery was evaluated for differentiating among rangeland cover types on the Welder Wildlife Refuge in south Texas. Unsupervised image analysis techniques were used to identify major cover types with overall accuracies ranging from $79 \%$ to $89 \%$. These results indicate that QuickBird imagery can be a useful tool for identifying rangeland cover types at a regional level.

\section{Challenges of Integrating Geospatial Technologies Into Rangeland Research and Management}

\section{Keith T. Weber}

This paper describes many of the tools and techniques available for geospatial analysis and provides suggestions to 
users to promote use of these tools. Of critical importance are 1) coregistering field samples with satellite imagery to ensure that the field sample is inside the correct pixel and 2) using GIS and satellite imagery to accurately map and monitor rangelands. Land managers have an increasing number of duties and a limited amount of time. It is impractical to monitor rangelands without the application of geospatial tools.

\section{Estimating Biophysical Characteristics of Musk Thistle (Carduus nutans) With Three Remote Sensing Instruments}

Mustafa Mirik, Karl Steddom, and Gerald J. Michels Jr.

Identifying the dynamics and extent of noxious weeds in a spatial and temporal context improves monitoring, planning, and management. Musk thistle (Carduus nutans L.), a noxious weed, is a good candidate for detection by remote sensing platforms because it may produce a unique spectral signature. This study indicated that normalized difference and simple ratio indices can be used for specific applications such as detection of musk thistle's biophysical variables in rangelands. These results can produce a map of parameters useful in determining the size of infestation and the reduction in rangeland productivity.

\section{Measured Sediment Yield Rates From Semiarid Rangeland Watersheds}

\section{H. Nichols}

Sediment is one of the principle pollutants of surface water in the United States; however, data describing long-term sediment yield rates on semiarid rangeland watersheds are relatively rare. Sediment yields from 8 subwatersheds within the US Department of Agriculture-Agricultural Research Service Walnut Gulch Experimental Watershed in southeastern Arizona were computed from stock-pond sediment measurements. Sediment accumulation records ranging from 30 to 47 years were evaluated for subwatersheds ranging in size from 35.2 to 159.5 ha. Sediment yield ranged from 0.5 to $3.0 \mathrm{~m}^{3} \cdot \mathrm{ha}^{-1} \cdot \mathrm{y}^{-1}$. This research is providing information that can be used to evaluate the impacts of watershed management on downstream sediment yield.

\section{Seed Production and Dispersal of Sulfur Cinquefoil in Northeast Oregon}

Kathleen A. Dwire, Catherine G. Parks, Michael L. Mclnnis, and Bridgett J. Naylor

Sulfur cinquefoil is an invasive herbaceous perennial that is rapidly spreading throughout the interior Pacific Northwest. We measured seed production and dispersal at infested sites in different habitats in northeast Oregon. Annual seed production was approximately 6,000 seeds per plant; seeds (achenes) were dispersed from July through mid-October and approximately $83 \%$ of the seeds were captured within $60 \mathrm{~cm}$ of the source plants. These results suggest that once sulfur cinquefoil reaches a site, it spreads and persists by releasing numerous viable seeds near parent plants. Prevention of annual seed set and dispersal will assist in managing the local expansion of sulfur cinquefoil.

\section{Vegetation on Gunnison's Prairie Dog Colonies in Southwestern Colorado}

\section{Madeline N. Grant-Hoffman and James K. Detling}

Research focused on black-tailed prairie dogs has often been extrapolated to other prairie dog species. We studied the effects of Gunnison's prairie dogs on plant cover and biomass, canopy height, and nitrogen concentration. We found no significant differences in plant cover and biomass, canopy height, and plant diversity on and off Gunnison's prairie dog towns, and only 1 of 4 focal plants showed a significant difference in nitrogen concentration on and off towns. This research indicates that the magnitude of differences on and off prairie dog towns may be dependent on the ecosystem and species of prairie dog.

Elk, Mule Deer, and Cattle Foraging Relationships on Foothill and Mountain Rangeland

Wendy L. F. Torstenson, Jeffrey C. Mosley, Tracy K. Brewer, Michael W. Tess, and James E. Knight

Knowing when and where significant foraging niche overlap is likely to occur can help resource managers sustain wild and domestic ungulates in the northern Rocky Mountains. We studied food habits and grazing distribution of elk, mule deer, and cattle and found that elk in spring had high foraging niche overlap with cattle in summer and fall. That is, in spring, elk foraged in many of the same places (largely foothill sagebrush grasslands) and ate diets (principally perennial bunchgrasses) similar to what cattle did in summer and fall. We recommend that resource managers focus their forage utilization and rangeland trend monitoring in foothill sagebrush grasslands.

\section{Restoration of Quaking Aspen Woodlands Invaded by Western Juniper}

Jonathan D. Bates, Richard F. Miller, and Kirk W. Davies

Western juniper woodlands are rapidly replacing lower elevation quaking aspen stands in the northern Great Basin. We evaluated 2 juniper removal treatments involving partial cutting of juniper trees to increase cured surface fuel loads, followed by fall burning or spring burning. The fall burn was more effective at eliminating remaining juniper and stimulating aspen suckering, whereas the spring burn was more effective at increasing understory cover and diversity. The study demonstrates that partial cutting of conifers followed by prescribed fire is effective at restoring aspen woodlands and that the severity of the burning disturbance is influenced by season of burn. 


\section{Response of Two Semiarid Grasslands to a Second Fire Application}

Carleton S. White, Rosemary L. Pendleton, and

Burton K. Pendleton

Degraded rangelands contribute sediment that lowers stream water quality; these degraded rangelands are also susceptible to invasion from woody plants. We reintroduced fire to 2 semiarid grasslands to try to stimulate grass production and reduce cover of woody plants. Fire reduced cover of juniper shrubs and trees, reduced the number of cholla cactus and the size of prickly pear cactus, but the loss of total plant cover after the fires increased the potential for greater erosion until plant cover returned. The benefits of returning fire to grasslands must be balanced with the cost of higher potential erosion.

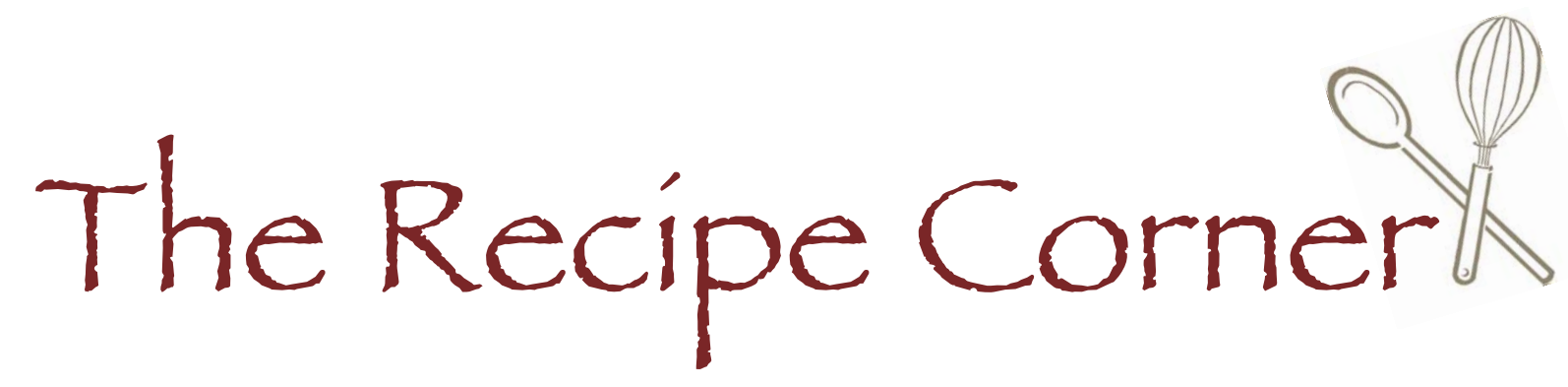

Editor's Note: There are many "family" recipes that are passed from generation to generation and never seen by outsiders. Many of these recipes would be enjoyed by others. This column has been established to present some of these recipes so others can enjoy them. The following recipe was submitted by Joe Brummer, Gunnison, Colorado, jbrummer@lamar.colorado.edu.

\section{Simple Dutch Oven Cobbler}

A lot of Boy Scout activities take place outdoors and include campfire cooking. This recipe was something I picked up when my son was in the Scouts.

2 (21-ounce) cans of your favorite pie filling (apple and cherry are my favorites)

1 box yellow cake mix

1 stick of butter or margarine

Build a campfire and let it burn down to the coals. For easier cleanup, I line my Dutch oven with aluminum foil. Place the pie filling on the bottom. Add the cake mix dry. Cut the stick of butter or margarine into thin pats and spread them over the top of the dry cake mix. Cover the oven with the lid and place over low to medium heat with some coals on top. Check after 30 minutes. This makes a heavy but rich cake on top of the pie filling. 